\title{
European council should back young investigators
}

\section{Support for junior researchers would be fair to all countries and disciplines.}

Sir - Robert May, in his Commentary article "Raising Europe's game" (Nature 430, 831-832; 2004) rightly argues for autonomy and scientific leadership for the proposed European Research Council (ERC), as well as emphasizing the need to promote scientific excellence and to foster young scientists.

There is broad consensus on these priorities. One could add the need for grants instead of the contracts that European Commission (EC) programmes currently use. Research is an evolutionary and creative process that requires flexibility; but with a contract, both the project and its outcome are fixed at the outset and the money can only be used according to these terms, except after uncertain, time-consuming renegotiation.

There is an urgent need to get the ERC up and running - preferably by January 2007 to coincide with the launch of EC Framework Programme 7. I suggest that this can be achieved by focusing initially on young investigators.

May argues cogently for a focus on excellence in basic research and a lean administration, using as comparison the US National Science Foundation (NSF). The aims are valid, but the comparison is not entirely appropriate. Each European Union (EU) country has its own agencies for developing science policies and funding research. The ERC, with a potential budget of $€ 1$ billion (US $\$ 1.26$ billion), is not meant to compete with or replace these bodies, but to bring a new European dimension. The scale and structure of the NSF (40 divisions, 250 programmes and 1,500 staff on a budget of $\$ 5.5$ billion) cannot be replicated in Europe, as it will require much closer European integration at all levels.

The success, or otherwise, of the ERC will depend on satisfactory responses to two major challenges: political endorsement and scientific acceptance. Politicians in certain countries fear the absence of juste retour: a share of the funding proportional to their contribution. This fear is exacerbated by concerns that their scientists will struggle to compete successfully in an ERC based exclusively on scientific excellence. Scientists also worry that the ERC will suffer from the same oversubscription problems as do existing EU programmes.

There is one way forward that could address these concerns, help keep the ERC manageable and be acceptable to many.
I recommend that the initial programmes of the ERC should focus predominantly, if not exclusively, on supporting young investigators who are establishing their first independent group. These programmes should go beyond existing European initiatives, such as the young investigator awards distributed by the European Heads of Research Councils, or the Wellcome Trust career development schemes.

This approach would meet with approval from the scientific community in most, if not all, disciplines. It would put all countries on an equal footing, for they all have excellent young researchers. It would be easier and quicker to implement than programmes with defined research priority areas, and should reduce the problem of oversubscription by reducing the potential customer base. And it would have a real impact on the European science base. This could help to define the ERC's visibility, usefulness and long-term prospects, laying the foundation for further development.

Luc Van Dyck

Initiative for Science in Europe (ISE),

clo European Life Sciences Forum,

Meyerhofstrasse 1, D-69117 Heidelberg, Germany

\section{US rules on tech transfer to foreign nationals}

Sir - I would like to respond to your News story "US universities up in arms over licence plans for foreign staff" (Nature 431, 615; 2004), for which I was interviewed. Although the US Department of Commerce appreciates Nature's coverage of this important issue, it is necessary to correct certain inaccuracies regarding US export control policy for technology transfer to foreign nationals.

First, the article says that a "change ... is being proposed by the [commerce] department". The department's independent inspector-general has indeed recommended certain revisions, but the department itself has not proposed any change.

Second, the story states: "Historically, universities and government laboratories doing basic research have been exempt from these rules." This is incorrect. Although there are exceptions for some technology transfers by the research community (such as for 'educational information' or for technology that arises during fundamental research), the long-standing regulations have never provided a blanket exception for the research community from the technology-transfer rules.

Third, the article repeatedly suggests that a licence would be required merely because a foreign national operates equipment that the United States controls for export. This too is incorrect. It is the transfer of controlled 'use' technology to foreign nationals (for example, training someone in how to use controlled equipment) that may require a licence, not merely the use of such equipment. In other words, there is a critical distinction absent from your article — between the transfer of controlled 'use' technology, and the use of controlled equipment, which does not require a licence.

Finally, the article incorrectly attributes to me the statement that "a licence would be required if technologically significant information was gained from using the equipment". The point I made was that only certain 'use' technology is sensitive: not all technology for using controlled equipment is controlled. Moreover, assuming that sensitive information was gained from using equipment, the information would not be controlled if it resulted from fundamental research.

Given the complex public-policy issues involved here, it is crucial for all stakeholders to have an accurate understanding of the situation (see also
www.bis.doc.gov/DeemedExports/ DeemedExportsFAQs.html).

\section{Peter Lichtenbaum}

Assistant secretary for export administration, US Department of Commerce, Washington DC 20230, USA

\section{Industry funding doesn't influence our reports}

Sir - U. Rangan and J. Shecter of Consumers Union, in Correspondence (Nature 431, 505; 2004), comment on our industry funding. Members of our Scientific Advisory Panel, which at present consists of more than 350 leading scientists and physicians, independently review all our scientific publications. These reviewers, of whom Joseph Rosen is one, serve on our advisory board and critique our work without compensation, just as reviewers of publications such as Nature do. We have never allowed, and will never allow, a funding body to influence our scientific positions. Interested parties can access our publications at www.acsh.org. Ruth Kava

American Council on Science and Health, 2nd floor, 1995 Broadway, New York,

New York 10023-5860, USA 